\title{
Difference Analysis on Meteorological Response Factors of Potential Evapotranspiration on Different Time Scales - Taking Beijing Station as an Example
}

\author{
liu hui ${ }^{1}$, Songjun $\operatorname{Han}^{1}$, and Zhang Baozhong ${ }^{1}$ \\ ${ }^{1}$ China Institute of Water Resources and Hydropower Research
}

May 5, 2020

\begin{abstract}
The response of meteorological elements to potential evapotranspiration(ET0) varies greatly from different time-scale perspectives, but current research are mainly focused on a certain time-scale and lack the study on the response of various meteorological elements to ET0 variations based on different time-scale perspectives. This situation results in the unilateral perception of variations in ET0 caused by climate change. Therefore, this study qualitatively explore the sensitive factors of ET0 on different time scales by sensitivity coefficients, and quantitatively characterize the actual contribution amounts of major meteorological elements to variations in ET0 on different time scales by contribution rate combining the sensitivity coefficients with the relative variation rates of meteorological elements. Results are listed as follows. (1) The SRH is always negative, but SRn, ST and SU are positive. The main sensitivity factors of ET0 vary on different time scales. Specifically, RH and Rn become the major sensitive factors alternately within a year. On an interannual basis, the Rn was the most sensitive factor from 1958 to 1963 , and the most sensitive factor became RH from 1964 to 1978. RH and Rn became the most sensitive factors to ET0 alternately from 1979 to 2017. (2) The contributions of each meteorological element fluctuate significantly. On the daily time scale, the GT and GU are large at the beginning and end of the year. The GRn and GRH are dominant in the middle of the year. On the monthly and seasonal time scales, RH contributes the most in spring and autumn and Rn does in summer. The GT and GU are dominant in winter. On the yearly and multi-yearly time scales, the main contributing factors are RH and T. In summary, the increase in ET0 in Beijing area is mainly caused by the decrease in RH and the increase in T. The decreases in U and Rn also slow down the further increase in ET0 in this area. This blocking effect caused by Rn in summer is highly evident.
\end{abstract}

\section{Hosted file}

Main Document.pdf available at https://authorea.com/users/303814/articles/434063-differenceanalysis-on-meteorological-response-factors-of-potential-evapotranspiration-ondifferent-time-scales-taking-beijing-station-as-an-example 
Table 1 Variation characteristics of trend rates and sensitivity coefficients of main meteorological elements on the monthly and seasonal scales

\begin{tabular}{|c|c|c|c|c|c|c|c|c|c|c|}
\hline \multirow{2}{*}{$\begin{array}{l}\text { Time } \\
\text { scale }\end{array}$} & \multicolumn{5}{|c|}{ Meteorological trend rate } & \multicolumn{4}{|c|}{ Sensitivity coefficient $(\%)$} & \multirow{2}{*}{$\begin{array}{l}\text { Sensitivity } \\
\text { factor }\end{array}$} \\
\hline & $\begin{array}{l}\text { Trend }_{\mathrm{T}} \\
\left({ }^{\circ} \mathrm{C} / 10 \mathrm{a}\right)\end{array}$ & $\begin{array}{l}\text { Trend }_{\text {RH }} \\
(\% / 10 a)\end{array}$ & $\begin{array}{l}\text { Trend }_{U} \\
(\mathrm{~m} / \mathrm{s}) / 10 \mathrm{a}\end{array}$ & $\begin{array}{l}\operatorname{Trend}_{R_{n}} \\
{\left[\left(\mathrm{MJ} / \mathrm{m}^{2}\right) / \mathrm{d}\right] / 10 \mathrm{a}}\end{array}$ & $\begin{array}{l}\operatorname{Trend}_{E T P} \\
(\mathrm{~mm} / 10 \mathrm{a})\end{array}$ & ST & SRH & su & SRn & \\
\hline Jan & 0.43 & 0.40 & -0.13 & -0.01 & -0.40 & 20.2 & -63.1 & 49.6 & 20.7 & \\
\hline Feb & 0.58 & -1.20 & -0.09 & -0.06 & 0.82 & 9.2 & -55.2 & 36.5 & 34.5 & RH \\
\hline Mar & 0.65 & -2.90 & -0.07 & -0.11 & 2. 83 & 25.0 & -47.4 & 28.5 & 44.1 & \\
\hline Apr & 0.49 & -1.50 & -0.09 & -0.08 & 1. 67 & 45.9 & -42.2 & 25.5 & 51.2 & \\
\hline May & 0.37 & -1.30 & -0.04 & -0.21 & 0.91 & 51.3 & -40.2 & 21.3 & 60.7 & \\
\hline Jun & 0.23 & -0.60 & -0.01 & -0.42 & -2.08 & 50.0 & -45.2 & 16.4 & 69.9 & $\mathrm{Rn}$ \\
\hline Jul & 0.31 & -2.20 & 0.05 & -0.35 & 0.31 & 46.8 & -55.6 & 9.4 & 79.8 & \\
\hline Aug & 0.40 & -2.50 & 0.08 & -0.22 & 1. 86 & 45.8 & -56.2 & 8.4 & 81.3 & \\
\hline Sept & 0.44 & -1.70 & 0.02 & -0.24 & 0.65 & 46.7 & -61.1 & 16.3 & 70.6 & \\
\hline Oct & 0.38 & -1.70 & -0.02 & -0.14 & 0.76 & 40.7 & -75.0 & 28.0 & 55.0 & \\
\hline Nov & 0.27 & -1.50 & -0.09 & -0.04 & 0.20 & 19.5 & -92.1 & 45.6 & 30.6 & RH \\
\hline Dec & 0.39 & -0.90 & -0.09 & -0.03 & 0.24 & 9.3 & -81.4 & 55.2 & 16.6 & \\
\hline Spring & 0.50 & -1.90 & -0.07 & -0.14 & 0.09 & 44.4 & -42.9 & 24.6 & 52.5 & $\mathrm{Rn}$ \\
\hline Sunmer & 0.32 & -1.80 & 0.04 & -0.33 & 1. 62 & 47.6 & -52.8 & 11.5 & 76.9 & \\
\hline Autumn & 0.36 & -1.70 & -0.03 & -0.14 & -0.02 & 40.2 & -74.4 & 27.4 & 54.8 & RH \\
\hline Winter & 0.47 & -0.50 & -0.10 & -0.06 & 7. 77 & 10.9 & -64.3 & 47.0 & 24.1 & \\
\hline $\begin{array}{l}\text { Annual } \\
\text { mean }\end{array}$ & 0.41 & -1.47 & -0.04 & -0.16 & 0.65 & 34.2 & -59.6 & 28.4 & 51.3 & RH \\
\hline
\end{tabular}

Table 2 Contribution amounts of various meteorological elements to ET0 on the monthly and 
Figure 1 Study area and location of the Beijing region in China

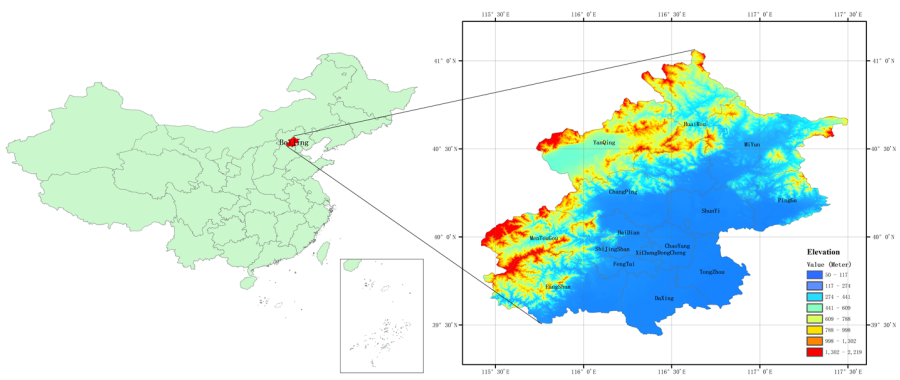

Figure 2 Variation characteristics of main meteorological elements and $\mathrm{ET}_{0}$ multi-yearly mean value within a year
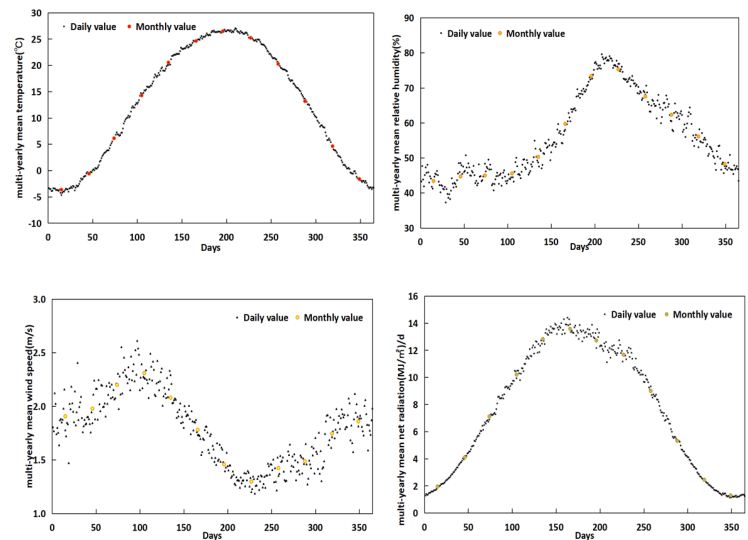